\title{
O Rio Grande de São Pedro sob o olhar de um português: Domingos José Marques Fernandes (1804)
}

\author{
Rio Grande de São Pedro through the look of a Portuguese: \\ Domingos José Marques Fernandes (1804)
}

Véra Lucia Maciel Barroso*

Resumo: O cenário da Capitania do Rio Grande de São Pedro, no século XIX, descortina-se como um espaço motivador a registros de viajantes e cronistas estrangeiros, que se debruçaram sobre ele, com interessantes observações. É o caso do português Domingos José Marques Fernandes, nascido na freguesia de São Salvador do Couto de Pedralva - Braga, que, em 10 de setembro 1804 , ofereceu "como amigo do Estado" a D. João, príncipe do Brasil e Regente de Portugal, Algarves e seus domínios, uma "Descrição Corográfica, Política, Civil e Militar" da Capitania. Sua intenção foi a de informar sobre sua situação, por ele constatada, e recomendar ao soberano, ações para promovê-la e ganho do Estado português. Trata-se de documento de, aproximadamente, 90 páginas, em quatro capítulos, abordando sua geografia física e humana, além de seus principais povoados. A, seguir, registra seu potencial econômico, para o que aponta as conveniências de animar seu povoamento. A análise do documento, ainda pouco conhecido, destaca sua relevância e significado para o conhecimento do extremosul, logo após a conquista portuguesa, do referido território, definitivamente conquistado aos espanhóis, em 1801, e definido pelo Tratado de Badajós, do mesmo ano.

Palavras-chave: Cronista português. Capitania do Rio Grande de São Pedro. Descrição. Documento.

Abstract: The scenario of the Captaincy of Rio Grande de São Pedro, in the nineteenth century, reveals itself as a motivating space in the records of travelers and foreign chroniclers, who make interesting observations. This is the case of the Portuguese Domingos José Marques Fernandes, born in the Parish of São

* Doutora em História (PUCRS), Membro Efetivo do Instituto Histórico e Geográfico do Rio Grande do Sul, Professora da FAPA e Historiadora do Centro Histórico-Cultural Santa Casa de Porto Alegre. 
Salvador do Couto do Pedralva - Braga, who, on September 10, 1804, offered "as a friend of the State" to D. John, Prince Regent of Brazil and Portugal, Algarve and its domains, a "Chorographic, Political, Civil and Military description "of Captaincy. His intention was to inform about the situation, he had noted, and recommend to the sovereign, actions to promote it and the gain of the Portuguese State. It is a document of about 90 pages, in four chapters, covering its physical and human geography, and its major villages. Next, he registers its economic potential, pointing to the positive points in developing the settlement. The analysis of the document, still little known, emphasizes its relevance and significance to the knowledge of the far south, soon after the Portuguese conquest of that territory, taken from the Spanish in 1801, and defined by the Treaty of Badajoz of the same year.

Keywords: Portuguese Chronicler. Captaincy of Rio Grande de São Pedro. Description. Document.

O século XIX chega para o Rio Grande do Sul anunciando a vinda de muitos visitantes. Por diferentes razões, motivos e objetivos, europeus se dirigiram ao extremo-sul do Brasil, viajando pelo território, há pouco, então, legitimado aos portugueses. A contar de 1801, enfim, desaparecia do cenário a linha imaginária - Tordesilhas -, que, desde o século XV, impusera seus limites na faixa meridional sulamericana até o litoral catarinense, ficando aos espanhóis o espaço riograndense do sul. Assim, a partir do Tratado de Badajós, que dera esse novo formato à região, a trajetória portuguesa foi de apropriação, de apossamento e de construção da pertença de um território tão disputado, representado por conflitos bélicos e diplomáticos por mais de um século.

Portanto, os anos de 1800 são de conhecimento e reconhecimento do Rio Grande do Sul, para muitos: para os "de casa" - assim se pode referir aos portugueses - e para "os visitantes" - os estrangeiros.

É interessante destacar que a agenda com o registro de viajantes estrangeiros dirigidos ao sul do Brasil indica uma maior representação francesa, seguida de outros europeus, instigando a 'nossa' curiosidade para o silenciamento de portugueses nesse inventário. Não é difícil explicar essa ausência de reconhecimento. Afinal, os portugueses eram ou tinham sido os colonizadores, o que tornava natural a sua presença e condição nos espaços em que se encontravam na América.

Lusos, do continente, ou insulares, dos arquipélagos dos Açores e Madeira, não se eximiram da condição de cronistas, mesmo que viessem para desempenhar alguma função confiada pelo Estado 
metropolitano. Nessa categoria de "passageiro temporário", em missão, alguns portugueses se puseram a registrar o que observaram, viram e constataram. É o caso do Sargento-Mor Domingos José Marques Fernandes, personagem, ora abordado, cuja escolha tem um significado e relevância para a história política e administrativa local, mas é um "ilustre" desconhecido pela maioria dos pesquisadores que tratam do Rio Grande do Sul. Ele vivenciou a realidade da Capitania em época pendular da história regional. Foi uma época de decisão - de definição -, ou seja, um momento divisor de águas, quando se definia o rumo da propriedade da área - após o século XVIII, sobretudo, de disputa imperialista entre as coroas ibéricas no Cone Sul. E o personagem escolhido para estudo teve um papel singular nesse processo. Nesta oportunidade, se pretende dar a ele o lugar que lhe cabe na costura que vai ser empreendida para efetivar, com êxito, a sonhada conquista portuguesa do Rio Grande do Sul.

\section{Uma crônica propositiva}

Ao apresentar-se o português Domingos José Marques Fernandes, de imediato registra-se que ele é um cronista marcado por uma postura propositiva e que reconheceu a dimensão de sua responsabilidade frente ao poder real que lhe designou vir ao Rio Grande do Sul cumprir missão. Ou seja, ele seguiu um roteiro do tipo ver, julgar e agir. Dito de outra forma, Marques Fernandes viu "o Rio Grande", constatou sua realidade e encaminhou sugestões ao Príncipe Regente, em proteção ao território, sobre cuja conquista acompanhou, registrou e vislumbrou os riscos e possibilidades de seu futuro.

Afinal, quem é esse português que chegou ao Rio Grande do Sul em 1798 e retornou a Portugal para entregar a D. João sua crônica em mãos, no ano de 1804 ?

Domingos José Marques Fernandes nasceu na freguesia de São Salvador do Couto de Pedralva, então arcebispado de Braga.

Considerado um homem de letras e observador arguto, depois de estar por seis anos no Rio Grande do Sul, de volta a Portugal ele viveu próximo da Corte. Com a vinda da família real, em 1808, Marques Fernandes voltou ao Brasil, vindo a ocupar cargo, junto ao governo português, na Serventia do Ofício de Escrivão do Crime. Casando no Rio de Janeiro, fixou residência na Ilha Grande, tendo sido também Juiz de Paz da Câmara da cidade em 1828. A última notícia que dele se tem é do ano de 1842 . 
Quando veio pela primeira vez ao Brasil, ele dirigiu-se ao extremosul. A partir de Porto Alegre, fez seus deslocamentos e contatos, que lhe permitiram prospectar, em cenário, as potencialidades do amplo território que vislumbrava. A partir dessa atuação, redigiu sua crônica intitulada Descrição Corográfica, Política, Civil e Militar da Capitania do Rio Grande de São Pedro, ${ }^{1}$ datada de 10 de setembro de 1804 . Ele a dedica ao Príncipe Regente D. João - afirmando ser amigo do Estado, pretendendo dar a ele uma instrução no sentido de aumentar o seu comércio com a manutenção do território que descreve, depois de por ele passar, verificar e ter, portanto, condições de demonstrar o seu potencial e retorno que adviria com ele, se mantido e resguardado ao domínio lusitano.

No encaminhamento de sua crônica entregue na torna viagem, ele vislumbra as vantagens que teria o reino com a preservação do território há pouco conquistado - cujo aumento do estado ele arrazoa com vivo otimismo -, quando diz:

[...] verá, Senhor, quão vasto território, quão fértil amena e deliciosa é a mesma Capitania; que nobres almas ali nascem e se criam; que hábeis engenhos; que generosos espíritos, e que fiéis vassalos alentam e vivificam aquele feliz clima, e Deus Nosso Senhor sujeitou ao domínio de V. Alteza Real; vassalos verdadeiramente portugueses, amantes do seu Príncipe com preferência a todo o respeito humano, [...]. Entendi, portanto, que eu não devia deixar de informar a V. Alteza Real do que sei, que é aquela Capitania; porque a medi, e das façanhas dos seus vassalos, porque as presenciei; [...] deduzindo, finalmente, quanto a mesma Capitania pelos serviços de seus habitantes e preciosidade de seus tributos se faz merecedora, de que V. Alteza Real se digne mandar promover as Providências, de que ela necessita para seu aumento, e do Estado (Fernandes, 1961, p. 12).

1 O Instituto Anchietano de Pesquisas obteve uma cópia do manuscrito original e o publicou em sua revista intitulada Pesquisas, a saber: FERNANDES, Domingos José Marques. Descrição Corográfica, Política, Civil e Militar da Capitania do Rio Grande de São Pedro do Sul, 1804. Pesquisas: História, Porto Alegre: Instituto Anchietano de Pesquisas, a. 5, p. 15,1961 . 


\section{O AMIGO DO ESTADO}

que, pela presente

DESCRIÇÃO COROGRÁFICA, POLÍTICA, CIVIL E

MILITAR

Da Capitania do Rio Grande de São Pedro do Sul, pretende dar uma instrução acomodada ao aumento do Comércio, e recomendar ao Soberano e à Posteridade os Varões célebres da mesma Capitania pelas suas ações em serviço do mesmo Soberano,

\section{O SERENISSIMO SENHOR}

DOM JOÃO,

PRÍNCIPE DO BRASIL E REGENTE DE PORTUGAL,

ALGARVES E SEUS DOMÍNIOS.

Etc., Etc., Etc.

AO QUAL

A - dedica seu autor e fiel Vassalo do mesmo

SENHOR

O Sargento-Mor

DOMINGOS JOSÉ MARQUES FERNANDES, natural da freguezia de S. Salvador do Couto de Pedralva, no Arcebispado de Braga, Primaz das Espanhas.

Figura 1. Folha de rosto do manuscrito de Marques Fernandes (Fonte: Fernandes, 1804. In: Pesquisas, 1961, p. 11).

Para alguns, o trabalho de Domingos José Marques Fernandes é considerado como que "A primeira história gaúcha"2 (Fernandes, 1804. In: Pesquisas, 1961, p. 5-9), pelos informes que oferece, pelos detalhes

2 Tal afirmação consta não só na folha de rosto da revista Pesquisas que acolheu a Descrição de Marques Fernandes, como está referido no prefácio da mesma publicação. 
que analisa sobre uma área que ainda não tivera uma descrição tão minuciosa como a que fizera, ainda que anteriores descrições e relatos já tivessem dado uma ideia panorâmica sobre a Capitania, como as de Sebastião Betâmio (de 1790) e de Francisco João Roscio (datado de 1781). ${ }^{3}$

O primeiro capítulo da Descrição aborda a geografia física do território do Rio Grande do Sul e tem como título: "Mostra-se qual e quanta seja a Capitania do Rio Grande de São Pedro do Sul, pelos efeitos da Criação, da Natureza e da Divina Providência". Trata da extensão da Capitania, seu porto, seus rios, suas ilhas e lagoas, serras e coxilhas, além de discorrer sobre as comunicações por terra e navegação. $\mathrm{O}$ cronista é detalhista na análise da hidrografia da Capitania, oferecendo subsídios para o conhecimento das redes d'água e suas possibilidades econômicas. Aos que se ocupam com a Geografia do Rio Grande do Sul, o documento em análise é fonte preciosa para dimensionar física e economicamente o território sulino; inclusive informa sobre a toponímia dos acidentes geográficos que alude.

No segundo capítulo, "Mostra-se qual e quanto seja esta Capitania pelos efeitos da propagação indestrutiva e providência humana", Marques Fernandes informa sobre a corografia, bem como a geografia humana e econômica da área constatada por ele. Informa sobre o número de habitantes, indica as principais povoações e com mais detalhes discorre sobre a mais antiga, a de Rio Grande, e depois foca a capital, Porto Alegre, com minúcias, sem esquecer-se das suas freguesias adjacentes: Aldeia dos Anjos e Viamão. Pelo Jacuí, seguiu até Rio Pardo, passando por Triunfo, depois se dirigiu ao Litoral Norte e aos Campos de Cima da Serra, indicando suas povoações e o que elas ofereciam de riqueza, como frutas e muito trigo: "e a cultura dele, nem é difícil nem prejudicial aos lavradores: há terras que produzem cinquenta por um; e de ordinário vendem vinte por um" (Fernandes, 1961, p. 45). Não esqueceu-se da pecuária e da exportação dos seus gêneros, bem como dos animais de caça e dos riscos de enfrentamento nas florestas ainda densas e com animais ferozes.

Sobre a capital, a sua descrição é alvissareira:

Já dissemos que de Porto Alegre se navega para cinco diversas partes da Capitania, agora dizemos que qualquer delas é mais vantajosa que em Portugal a navegação do Ribatejo; com princípios que

As crônicas de Bettamio (Notícia Particular do Continente do Rio Grande) e Roscio (Compêndio Noticioso) estão publicadas na obra de Freitas (1980). 
prometem aumentar a mesma Capitania com excesso e vantagem a qualquer das outras do Brasil, pela facilidade que temos exposto do seu comércio por aqueles cinco rios para muitas terras e mui distantes [...] (Fernandes, 1961, p. 37).

Interessante é o apanhado que faz do número de habitantes, indicando inclusive as principais povoações existentes. Diz ele:

Haverá nesta Capitania cinquenta mil almas, distribuídas em vinte e uma freguesias, cujas igrejas paroquiais são quatorze matrizes e sete filiais; e subordinadas, quanto à religião, a cinco vigários de vara, postos pelo Excelentíssimo Bispo do Rio de Janeiro, que é o Ordinário do lugar, em cinco comarcas eclesiásticas, denominadas de S. Pedro do Sul, Porto Alegre, Rio Pardo, Triunfo e da Conceição do Arroio. [...]

A maior parte desta gente está reduzida a povoações; destas são três as principais, a saber: S. Pedro do Sul, Rio Pardo e Porto Alegre (Fernandes, 1961, p. 33).

Em sequência, vem o capítulo intitulado "Mostra-se qual e quanta seja a Capitania do Rio Grande de São Pedro do Sul, pela sua opulência e forças." É aqui que ele aborda as origens da extrema área meridional brasileira, desde as demarcações e lutas nas Missões, frente aos espanhóis, até a conquista do oeste, em 1801, liderada por Patrício Correia da Câmara, Manoel dos Santos Pedroso e Borges do Canto. Nessa descrição, chega a minúcias.

No último capítulo "Mostra-se qual e quanta pode vir a ser a mesma Capitania." Trata-se de uma antevisão do futuro do Rio Grande do Sul. Eis uma de suas passagens:

As melhores terras da Capitania do Rio Grande de S. Pedro do Sul para a agricultura infeliz e lastimosamente se acham incultas e perdidas; as mesmas que podem fazer a felicidade de muitas famílias, a defesa e a segurança da mesma Capitania na Coroa de Portugal e um considerável aumento de dízimos e direitos da mesma Coroa, existem como abandonadas, infrutíferas e inúteis (Fernandes, 1961, p. 82).

E segue o cronista apontando o potencial alvissareiro do nordeste do Rio Grande de São Pedro frente ao centro e nordeste brasileiro áreas não privilegiadas na sua análise -, diante das da Capitania que descrevia: 
[...] as terras da Serra Geral são as mais excelentes que há: começa esta no Rio das Torres, que, como também se disse divide esta Capitania da de Santa Catarina e corre por espaço de oitenta léguas, até à guarda dos ferreiros, ou boca do Monte, com largura de oito léguas e mais.

Podemos dizer que elas são as melhores terras, não só da Capitania do Rio Grande, mas de toda a América; porque segundo a experiência, que há de algumas, que se têm provado, não só produzem toda a espécie de legumes, mas também de cana-deaçúcar, com vantagem a todas as outras terras do Brasil na produção deste gênero, e com excesso de trinta a quarenta por cento: o que se vê em alguns engenhos, que ali se acham já estabelecidos; para isto concorrem duas grandes adições: muita madeira e boa; rios navegáveis para o transporte: de maneira que não haverá lavrador distante da navegação, pela qual possa exportar os efeitos da sua fazenda mais de seis léguas, fáceis a carros. E é tal a fertilidade das mesmas terras, que um quarto de légua em quadro é bastante para o estabelecimento de um engenho de açúcar do lote de cem escravos: quando nas outras Capitanias um engenho de açúcar deste mesmo lote pede meia légua quadrada (Fernandes, 1961, p. 82-83).

\section{E ousa mais, ao dizer:}

Em toda a América não há sítios mais próprios para fábricas de açúcar como nas mencionadas terras incultas daquela Capitania, pela experiência das que lhe são próximas, já reduzidas à cultura, como fica dito, porque quase todas têm águas altas, que podem fazer trabalhar os engenhos, o que lhes dá valor de mais uma quarta parte. Todos os alimentos e bestas necessárias se acham mais baratos na Capitania de que falamos, do que em qualquer outra; e o gasto de um engenho nela, ainda de menor labutação, será menor que em outra, três ou quatro mil cruzados, pelas comodidades ponderadas (Fernandes, 1961, p. 85).

É de considerar-se o que diz Marques Fernandes. Entretanto, nos estudos sobre a produção açucareira do Brasil, ele é um ilustre desconhecido. ${ }^{4}$

4 Quando da produção da tese da autora deste trabalho, sua crônica foi visitada e cotejada com outras fontes documentais do período. Verificar: BARROSO, Véra Lucia Maciel. Moendas caladas: Açúcar Gaúcho S. A. - AGASA: um projeto popular silenciado: Santo Antônio da Patrulha e Litoral Norte do Rio Grande do Sul (1957-1990). 2006. Tese (Doutorado em História do Brasil) - Programa de Pós-Graduação em História, Pontifícia Universidade Católica do Rio Grande do Sul, Porto Alegre. 
Mais adiante, seguindo o perfil de cronista propositivo, ele sugere o estabelecimento de 10.240 casais dos Açores ou vindos de outras capitanias brasileiras que se oferecesssem para povoar a área de fronteira viva. Então, percebendo a importância da conquista do território missioneiro e para fazer garantir sua área ao domínio português, evoca, em sua crônica, a urgente necessidade de aumentar a população da Capitania, para a segurança da Coroa, a quem servia no Rio Grande do Sul.

O corpus de sua crônica se alinha e se encaminha com insistência, no sentido de mostrar e demonstrar as potencialidades do território conquistado por Portugal. E dá a entender que valera o projeto, justificando palmo a palmo em cenário aberto, que retornos a coroa teria com o território, caso viesse a compor definitivamente os seus domínios. Mas, para garantia de efetivação desses ganhos, haveria que mais de perto ter a área guardada e vigiada. Seriam as câmaras municipais os eixos e pilares desse projeto, devendo cumprir uma rotina de trabalho que cuidasse da tarefa de vigília e prontidão guarnecedora das potencialidades anunciadas.

Assim, diante do que viu e observou, constatou que se tratava de importante área, cujos feitos em sua defesa e alargamento das fronteiras até então empreendidos por Portugal, somados ao valor de seu comércio e pecuária, não tinham sido em vão. Marques Fernandes então apontou a urgência em dividir a Capitania em grandes municípios como estratégia político-administrativa para resguardar o território que percebera tão rico e anunciador de retorno e promissão à metrópole. Assim recomenda: "A criação de seis vilas, e competentes ministros de justiça, que evitem as desordens e inclemências que os povos sofrem na distância de oitenta e noventa léguas do único ministro da Capitania do Rio Grande" (Fernandes, 1961, p. 87).

Tal foi seu empenho em manter o Rio Grande do Sul nos domínios de Portugal, que ele retornou a Lisboa com a proposição em mãos, do que resultou a determinação de D. João de que criassem suas quatro primeiras vilas, anos depois ao chegar ao Brasil. O príncipe, aqui mais de perto, e cercado por Marques Fernandes, não vacilou em aceder à proposição do "amigo e servidor" que viera conferir a Capitania dos seus domínios no extremo-sul. Efetivamente, em 1809, enfim, D. João criou as quatro primeiras vilas com seus competentes ministros da justiça para coibirem as desordens e inclemências que a população sofria, conforme alertara na Descrição. 


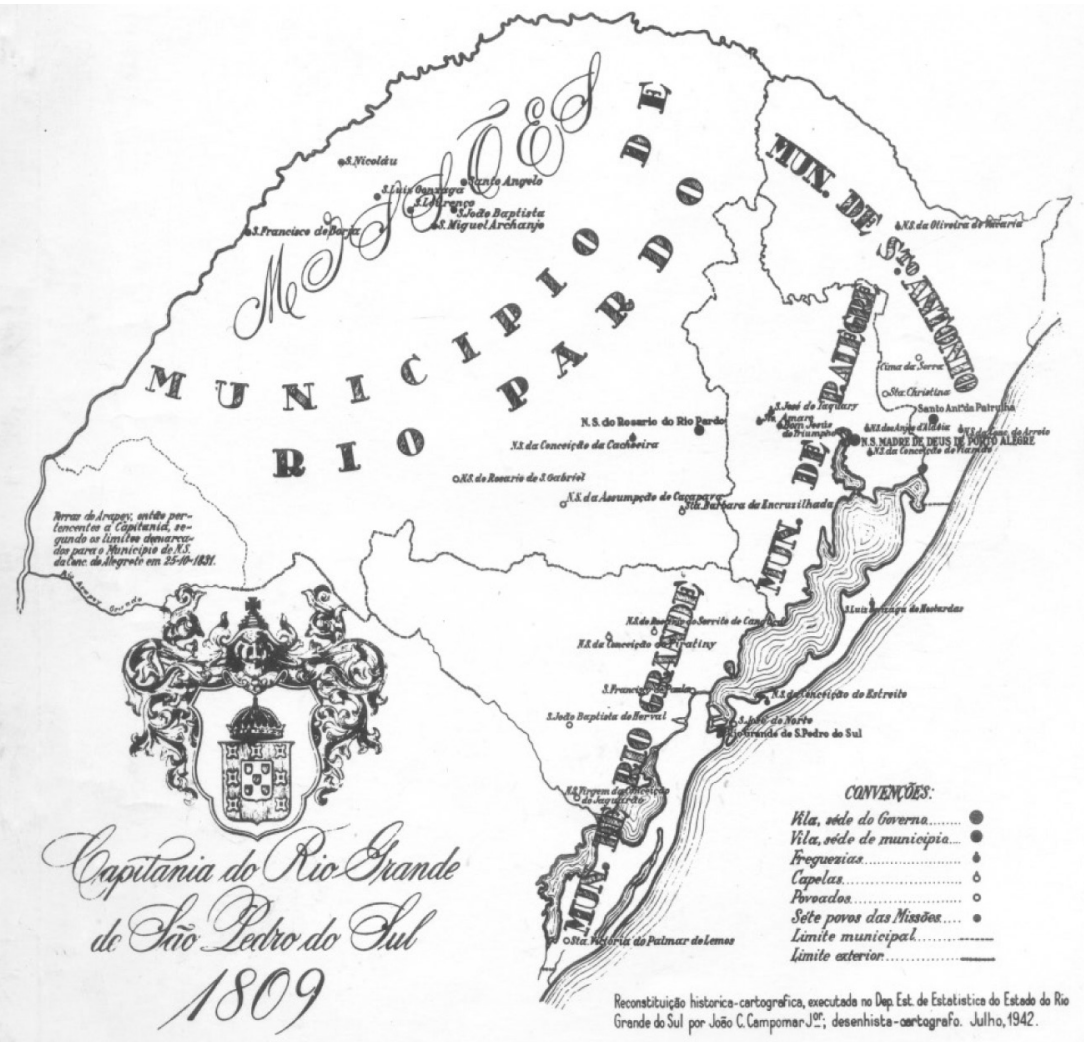

Figura 2. Mapa da Capitania do Rio Grande de São Pedro do Sul em 1809 (Fonte: FUNDAÇÃO DE ECONOMIA E ESTATÍSTICA. De Província de São Pedro a Estado do Rio Grande do Sul: censos do RS (1803-1950). Porto Alegre, 1986. v. 1. p. 46).

\section{Conclusão}

Entrava-se no século XIX, quando o Brasil se inventava. Configurava-se seu território "gigante", após o fim do traçado de Tordesilhas. O Rio Grande do Sul enfeixava-lhe no extremo da América Meridional.

Importa compreender o documento em análise no seu tempo. A Descrição de Marques Fernandes é um documento de viagem que se expressa como monumento. Aliás, para Jacques Le Goff, todo documento tem em si um caráter de monumento e guarda duas funções principais: "uma é o armazenamento de informações que permite comunicar através 
do tempo e do espaço, e fornece ao homem um processo de marcação, memorização e registro: a outra ao assegurar a passagem da esfera auditiva à visual, permite reexaminar, reordenar, retificar frases e até palavras isoladas" (Le Goff, 1990, p. 433). Em suma, considerar o documento como monumento torna possível perceber as condições de produção histórica e, logo, a sua intencionalidade inconsciente, ou até mesmo consciente. Nessa última condição se encontra o cronista português, que além de registrar, também propôs, com a percepção da conjuntura que o Brasil vivia, o da sua invenção.

É visível na leitura da Descrição do cronista português Marques Fernandes que não lhe escapou, nos anos em que esteve na Capitania do Rio Grande de São Pedro, vislumbrar as possibilidades que o território oferecia ao reino, e que, por isso, urgia "cuidá-lo"; para tanto, segundo ele, o rei devia estar atento e agir.

Na virada para o século XIX, em momento decisivo para o rumo da Capitania então há pouco conquistada, sob o seu olhar atento e curioso nos deslocamentos que empreendeu, Marques Fernandes teve condições de traçar um cenário positivo e cativante da extremadura sulina do Brasil.

Ao longo de sua crônica, desfilam pareceres que mostram as vantagens que a Capitania reúne, dando até a ideia de que ela era a melhor da América Portuguesa. Os atributos por ele enunciados revelam o seu vivo interesse para a região, reiterando o caráter estratégico e as vantagens econômicas que a mesma oferecia.

Dentre os viajantes europeus que percorreram o extremo-sul, ao longo dos anos 1800, pode-se afirmar que Marques Fernandes se diferencia dos demais pela descrição minuciosa que faz da Capitania, nas quatro partes em que divide a sua crônica.

As informações e a análise que oferece possibilitam depreender considerações que a ele como europeu se mostraram uma descoberta alvissareira. Não se revelou um detrator do espaço, nem de sua gente. Ao contrário: escreveu sob o signo de rasgados elogios, nas diferentes frentes que abordou e discorreu.

Na justificação que faz para a criação das vilas no Rio Grande de São Pedro, ou no conselho que dá para povoarem-se as terras incultas com açorianos, se mostra um viajante propositivo.

Percebe-se claramente, ao longo de sua crônica, que se mantinha firme em seu objetivo de convencer o Príncipe Regente para que dirigisse sua atenção e cuidado a um espaço de fronteira viva, que exigia do reino uma atitude preservacionista. 
Deve-se a Marques Fernandes o início do municipalismo gaúcho pela persistência com que se colocou pela criação das quatro primeiras vilas do Rio Grande do Sul, a saber: Rio Grande, Porto Alegre, Rio Pardo e Santo Antônio da Patrulha, oficializadas em 1809, através de Provisão de 7 de outubro, então anunciada por D. João VI, já no Brasil.

Retornando com a família real ao Brasil, em 1808, e junto à corte, Marques Fernandes não poupou esforços para consumar as recomendações que fizera em sua Descrição, agora mais perto do Príncipe Regente, no Rio de Janeiro.

Consumavam-se assim as recomendações que o Governador da Capitania Paulo José da Silva Gama fizera em 1803, sugerindo as mesmas povoações para encabeçarem as câmaras a serem criadas, para melhor cuidar do território, então há pouco conquistado, em 1801, depois de sucessivos embates e tratados entre as coroas ibéricas no Cone Sul.

\section{Referências}

BARROSO, Véra Lucia Maciel. Moendas caladas: Açúcar Gaúcho S. A. - AGASA: um projeto popular silenciado: Santo Antônio da Patrulha e Litoral Norte do Rio Grande do Sul (1957-1990). 2006. Tese (Doutorado em História do Brasil) - Programa de PósGraduação em História, Pontifícia Universidade Católica do Rio Grande do Sul, Porto Alegre.

BETTAMIO, Sebastião Francisco. Notícia Particular do Continente do Rio Grande. In: FREITAS, Décio. O capitalismo pastoril. Porto Alegre: EST, 1980.

FERNANDES, Domingos José Marques. Descrição Corográfica, Política, Civil e Militar da Capitania do Rio Grande de São Pedro do Sul, 1804. Pesquisas: História, Porto Alegre: Instituto Anchietano de Pesquisas, a. 5, n. 15, 1961.

FUNDAÇÃO DE ECONOMIA E ESTATÍSTICA. De Província de São Pedro a Estado do Rio Grande do Sul: censos do RS (1803-1950). Porto Alegre, 1986, p. 46, v. 1.

LE GOFF, Jacques. História e memória. São Paulo: Ed. da UNICAMP, 1990.

ROSCIO, Francisco João. Compêndio noticioso. In: FREITAS, Décio. O capitalismo pastoril. Porto Alegre: EST, 1980. 